\title{
2-Aminoethoxydiphenyl Borate Activates and Sensitizes the Heat-Gated Ion Channel TRPV3
}

\author{
Man-Kyo Chung, ${ }^{1}$ Hyosang Lee, ${ }^{1}$ Atsuko Mizuno, ${ }^{2}$ Makoto Suzuki, ${ }^{2}$ and Michael J. Caterina ${ }^{1}$ \\ ${ }^{1}$ Departments of Biological Chemistry and Neuroscience, Johns Hopkins School of Medicine, Baltimore, Maryland 21205, and ${ }^{2}$ Department of \\ Pharmacology, Jichi Medical School, Miamikawachi, Tochigi, 329-0498, Japan
}

\begin{abstract}
Six of the mammalian transient receptor potential (TRP) ion channel subtypes are nonselective cation channels that can be activated by increases or decreases in ambient temperature. Five of them can alternatively be activated by nonthermal stimuli such as capsaicin [transient receptor potential vanilloid 1 (TRPV1)] or hypo-osmolarity (TRPV2 and TRPV4). No nonthermal stimuli have yet been described for TRPV3, a warmth-gated ion channel expressed prominently in skin keratinocytes. Here, we demonstrate that 2-aminoethoxydiphenyl borate (2-APB), a compound used to inhibit store-operated $\mathrm{Ca}^{2+}$ channels and $\mathrm{IP}_{3}$ receptors, produces robust activation of recombinant TRPV3 in human embryonic kidney 293 cells with an $\mathrm{EC}_{50}$ of $28 \mu \mathrm{m}$. 2-APB also sensitizes TRPV3 to activation by heat, even at subthreshold concentrations. In inside-out membrane patches from TRPV3-expressing cells, 2-APB increases the open probability of TRPV3. Also, whereas heat alone is capable of activating TRPV3-mediated currents in only a small proportion of primary mouse keratinocytes, 2-APB activates heat-evoked, TRPV3-mediated currents in the majority of these cells. Together, these findings identify 2-APB as the first known chemical activator of TRPV3 and enhance the notion that TRPV3 participates in the detection of heat by keratinocytes.
\end{abstract}

Key words: 2-APB; TRPV3; heat; thermosensation; keratinocytes; temperature

\section{Introduction}

The mammalian nervous system evaluates temperature over a range extending from extreme cold to extreme heat. This capacity involves the selective activation of neuronal subpopulations that fire over discrete ranges of skin temperature. The identification of temperature-gated nonselective cation channels of the transient receptor potential (TRP) family has provided candidate mediators of this sensory diversity (Patapoutian et al., 2003). Transient receptor potential vanilloid 1 (TRPV1) is activated by temperatures $>42^{\circ} \mathrm{C}$ and is expressed most highly in a subpopulation of nociceptive neurons (Caterina and Julius, 2001). TRPV2, which is expressed in a distinct neuronal subpopulation, is activated at higher temperatures $\left(>52^{\circ} \mathrm{C}\right)$ (Caterina and Julius, 2001). TRPV3 (Peier et al., 2002b; Smith et al., 2002; Xu et al., 2002) and TRPV4 (Guler et al., 2002; Watanabe et al., 2002) both exhibit thresholds in the warm range $\left(>32^{\circ} \mathrm{C}\right)$. Although these two proteins have been detected immunologically in sensory neurons (Smith et al., 2002; Alessandri-Haber et al., 2003), their most robust cutaneous expression is in keratinocytes (Guler et al., 2002;

Received March 13, 2004; revised April 21, 2004; accepted April 23, 2004.

This work was supported by American Cancer Society Research Scholar Grant RGS-01-063-01-CSM and grants from The W. M. Keck Foundation, the Searle Scholars Program, and the Arnold and Mabel Beckman Foundation (M.J.C.). We thank Veit Flockerzi for mouse TRPV4 CDNA, David Clapham for human TRPV3 CDNA, Juan Wang for technical assistance, and Shin Kang, Pierre Coulombe, Craig Montell, and members of the Caterina laboratory for helpful suggestions.

Correspondence should be addressed to Dr. Michael J. Caterina, 408 Biophysics Building, Department of Biological Chemistry, Johns Hopkins School of Medicine, 725 North Wolfe Street, Baltimore, MD 21205. E-mail: caterina@jhmi.edu.

DOI:10.1523/JNEUROSCI.0934-04.2004

Copyright $\odot 2004$ Society for Neuroscience $\quad 0270-6474 / 04 / 245177-06 \$ 15.00 / 0$
Peier et al., 2002b), leading to speculation that keratinocytes cooperate with sensory afferents to signal elevated temperature. Transient receptor potential melastatin 8 (TRPM8) (McKemy et al., 2002; Peier et al., 2002a) and transient receptor potential ankyrin 1 (TRPA1) (Story et al., 2003) are reportedly activated by $\operatorname{cool}\left(<28^{\circ} \mathrm{C}\right)$ and cold $\left(<20^{\circ} \mathrm{C}\right)$ temperatures, respectively.

Most thermosensitive TRP channels can alternatively be activated by nonthermal stimuli. TRPV1 can be activated by capsaicin, protons, or endocannabinoids (Caterina and Julius, 2001). TRPV2 can be activated by hypo-osmolarity (Muraki et al., 2003) or growth-factor signaling (Kanzaki et al., 1999), and TRPV4 can be activated by hypo-osmolarity, arachidonic acid metabolites, or $4 \alpha$-phorbol dibutyryl didecanoate (Watanabe et al., 2003; Nilius et al., 2004). TRPM8 and TRPA1 can be activated by menthol (McKemy et al., 2002; Peier et al., 2002a) and pungent isothiocyanates (Bandell et al., 2004; Jordt et al., 2004), respectively. The prevalence of polymodality among these channels is consistent with the fact that they are expressed not only in external tissues but also internally, where temperature is less variable.

Given these findings, it might be expected that TRPV3, too, can be activated by nonthermal stimuli. However, no such stimuli have been reported to date. Another intriguing observation is that although TRPV3 immunoreactivity is detectable in a majority of cultured primary keratinocytes, $<3 \%$ of these cells exhibit TRPV3-like heat-evoked currents (Chung et al., 2004). To address these issues, we examined the possibility that known modulators of ion-channel activity might unmask or facilitate TRPV3 gating. We discovered that 2-aminoethoxydiphenyl borate (2$\mathrm{APB}$ ), a compound commonly used to inhibit $\mathrm{IP}_{3}$ receptormediated $\mathrm{Ca}^{2+}$ release or store-operated $\mathrm{Ca}^{2+}$ entry (Bootman 
et al., 2002), can activate recombinant TRPV3 and sensitize recombinant and native TRPV3 to heat in transfected cells and primary keratinocytes, respectively.

\section{Materials and Methods}

Cell culture. Wild-type C57BL/6 mice and TRPV4 -/- mice (Suzuki et al., 2003) were used. Procedures were approved by the Johns Hopkins Animal Care and Use Committee. Chemicals and culture reagents were obtained from Invitrogen (Carlsbad, CA) or Sigma (St. Louis, MO). Human embryonic kidney (HEK) 293 cells and primary mouse keratinocytes were cultured as described previously (Chung et al., 2003, 2004). cDNAs encoding mouse TRPV1, TRPV2, and TRPV3 (Chung et al., 2003), mouse TRPV4 (gift from Veit Flockerzi, Universitat des Saarlandes, Homburg, Germany), and human TRPV3 (gift from David Clapham, Harvard Medical School, Boston, MA), subcloned into a control vector (pCDNA3), were cotransfected with green fluorescent protein into HEK293 cells using Fugene 6 (Roche, Palo Alto, CA) and assayed after $15-36$ hr. Ratiometric calcium imaging using Fura-2 was performed as described previously (Guler et al., 2002).

Electrophysiology. For whole-cell voltage clamp, recording pipettes were filled with internal solution containing (in mM) 120 Cs-aspartate, 10 $\mathrm{CsCl}, 1 \mathrm{MgCl}_{2}$, 5 EGTA, and $10 \mathrm{HEPES}$, pH 7.4 with CsOH, $295 \mathrm{mOsm}$ with mannitol. Cells were superfused with bath solution containing (in mM) $130 \mathrm{Na}$-aspartate, $6 \mathrm{NaCl}, 2 \mathrm{CaCl}_{2}, 1 \mathrm{MgCl}_{2}, 10$ glucose, and 10 HEPES, pH 7.4 with $\mathrm{NaOH}, 305$ mOsm with mannitol. Pipette solution for inside-out patch clamp contained (in mM) $140 \mathrm{NaCl}, 5 \mathrm{EGTA}$, and 10 HEPES, pH 7.4 with $\mathrm{NaOH}$. $\mathrm{MgCl}_{2}(0.1 \mathrm{~mm})$ was added for bath perfusion. Keratinocytes were gently trypsinized before recording. An Axopatch 200B amplifier and pClamp 9.0 software (Axon Instruments, Union City, CA) were used. Borosilicate glass electrodes had tip resistances of 1.5-2 $\mathrm{M} \Omega$ (whole cell) and 3-6 $\mathrm{M} \Omega$ (single-channel recording). We recorded whole-cell currents only when the series resistance was $<7$ $\mathrm{M} \Omega$ without compensation. A KCl agar bridge was used. Data were corrected for liquid junction potential. Membrane capacitance was measured using a neutralization circuit. Data were low-pass filtered at $2 \mathrm{kHz}$ and digitized at $3.3 \mathrm{kHz}$ (whole cell) and $33 \mathrm{kHz}$ (single channel). Heat was delivered and monitored as described previously (Chung et al.,
2004). Data were expressed as mean \pm SEM. Unless otherwise indicated, comparisons were made using unpaired $t$ test. Dose-response relationships were fitted using the following equation: $y=E_{\max } /\left(1+\mathrm{EC}_{50} / x\right)$, where $E_{\max }$ is the maximal effect and $x$ is the agonist concentration.

\section{Results}

\section{2-APB activates TRPV3 in HEK293 cells}

We examined the effects of agents proposed to influence other TRP channels on recombinant TRPV3. One of these was 2-APB, a modulator of store-operated $\mathrm{Ca}^{2+}$ influx and $\mathrm{IP}_{3}$ receptormediated $\mathrm{Ca}^{2+}$ release (Bootman et al., 2002). 2-APB (32 $\left.\mu \mathrm{M}\right)$ evoked a slowly developing, robust, outwardly rectifying current when administered to mouse TRPV3-transfected HEK293 cells at $24^{\circ} \mathrm{C}$. Like heat-evoked TRPV3 currents (Peier et al., 2002b; Smith et al., 2002; Xu et al., 2002), 2-APB-evoked currents were reversible and sensitized with successive challenges. 2-APB also sensitized TRPV3-transfected cells to a subsequent heat stimulus (Fig. 1A). Cells expressing human TRPV3 exhibited comparably strong 2-APB-evoked currents (Fig. $1 B$ ). In contrast, no 2-APBevoked $(100 \mu \mathrm{M})$ currents were observed at $24^{\circ} \mathrm{C}$ in pCDNA3transfected HEK293 cells or cDNAs encoding the related channels, TRPV2 or TRPV4 (Fig. 1B). TRPV1-transfected cells exhibited a very weak 2 -APB-evoked increase in outward current at strong positive potentials (Fig. $1 \mathrm{~B}$ ). At $24^{\circ} \mathrm{C}$, small TRPV3 currents were observed in response to $3.2 \mu \mathrm{M} 2-\mathrm{APB}$, and the responses increased dose dependently $\left(\mathrm{EC}_{50}=28.3\right.$ at $+80 \mathrm{mV}$ and $41.6 \mu \mathrm{M}$ at $-80 \mathrm{mV}$ ), with apparent saturation between 100 and $320 \mu \mathrm{M}$ (Fig. 1C). At low 2-APB concentrations, TRPV3 currents exhibited strong outward rectification, like those evoked by heat. However, as 2 -APB was increased to $>10 \mu \mathrm{M}$, this outward rectification gradually evolved into dual rectification, with a clear difference from heat-evoked currents at negative potentials (Fig. 1A-C). 2-APB also sensitized heat-evoked TRPV3 current responses. At a dose $(1 \mu \mathrm{M})$ insufficient to evoke significant
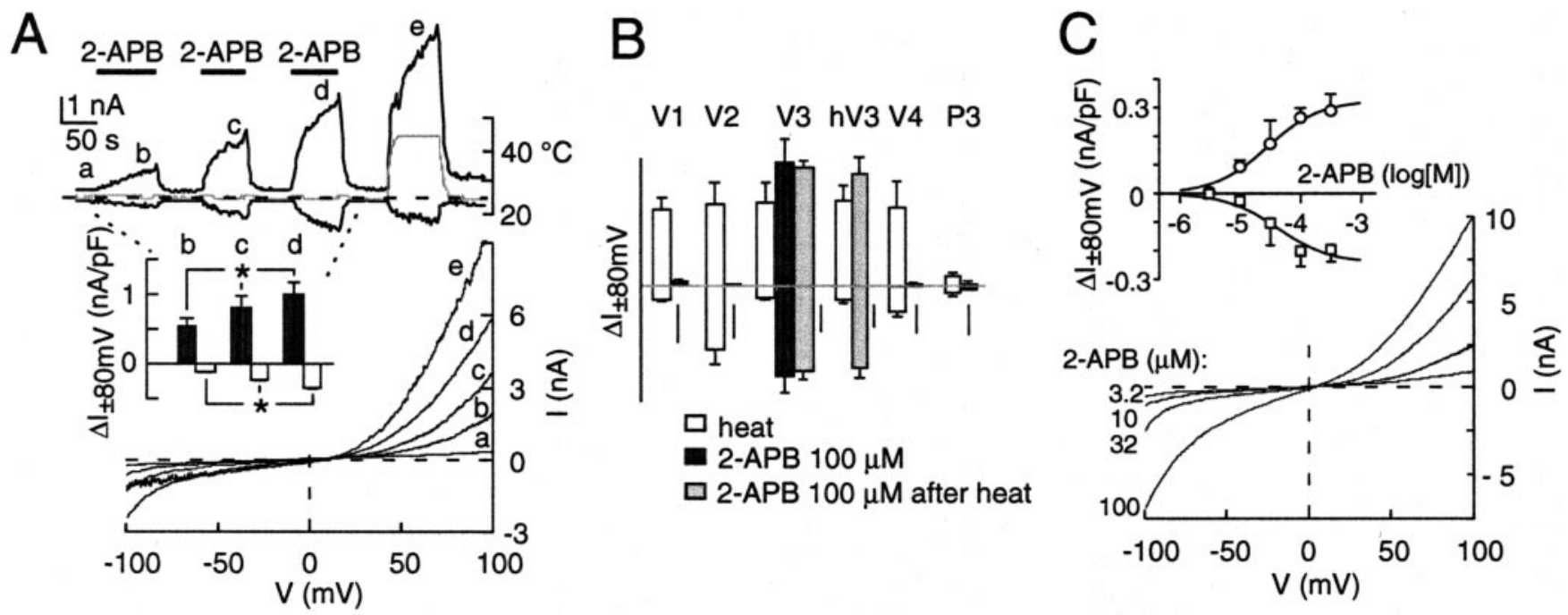

Figure 1. 2-APB activates recombinant TRPV3 in HEK293 cells. A, Top, Sensitizing whole-cell current responses of TRPV3-transfected HEK293 cells during successive applications of 2-APB (32 $\mu \mathrm{M}$ ) and subsequent challenge with heat $(+80 \mathrm{mV}$, upward; $-80 \mathrm{mV}$, downward). Traces were produced by connecting current amplitude (black line) or temperature (gray line) measurements recorded every $2 \mathrm{sec}$. Middle, Mean current amplitude change normalized to membrane capacitance at $+80 \mathrm{mV}$ (upward, filled bars) and $-80 \mathrm{mV}$ (downward, open bars) $\left(\Delta I_{ \pm} 80 \mathrm{mV}\right)$ after application of 2-APB, at indicated times $\left(n=5 ;{ }^{*} p<10^{-4}\right.$; one-way ANOVA). Bottom, $I-V$ traces obtained at times $a-e$ (shown at the top) during repetitive 200 msec voltage ramps from -100 to $+100 \mathrm{mV}$. The dashed line indicates zero current or potential level. V, Membrane potential; I, current. $B, \Delta I_{ \pm 80 \mathrm{mV}}$ recorded from HEK293 cells transfected with mouse TRPV1 (V1), TRPV2 (V2), TRPV3 (V3), and TRPV4 (V4), human TRPV3 (hV3), and pCDNA3 (P3). ForV1, V2, and V4, currents were evoked by $100 \mu \mathrm{m} 2$-APB (filled bars) followed by heat (open bars; V1, $47^{\circ} \mathrm{C} ; \mathrm{V} 2,55^{\circ} \mathrm{C}$; V4, $43^{\circ} \mathrm{C}$ ) after washout. For V3 and hV3, 2-APB (gray bars) was applied after heat ( $43^{\circ} \mathrm{C}$; open bars). Filled bars for V3 indicate 2-APB addition without previous heat application. $n=6$ in each group. Scale bars, V1, $0.5 \mathrm{nA} ; \mathrm{V2}, \mathrm{V4}, \mathrm{P3}, 50 \mathrm{pA} ; \mathrm{V} 3, \mathrm{hV} 3,0.1 \mathrm{nA}$. C, Top, $\Delta l_{ \pm 80 \mathrm{mV}}$ evoked in TRPV3-expressing HEK293 cells at $24^{\circ}$ C by different concentrations of 2-APB $(-80 \mathrm{mV}$, squares; $+80 \mathrm{mV}$, circles); $n=$ 6. Bottom, Representative traces from TRPV3-transfected cells at indicated 2-APB concentrations. Dashed lines indicate zero current or potential level. 

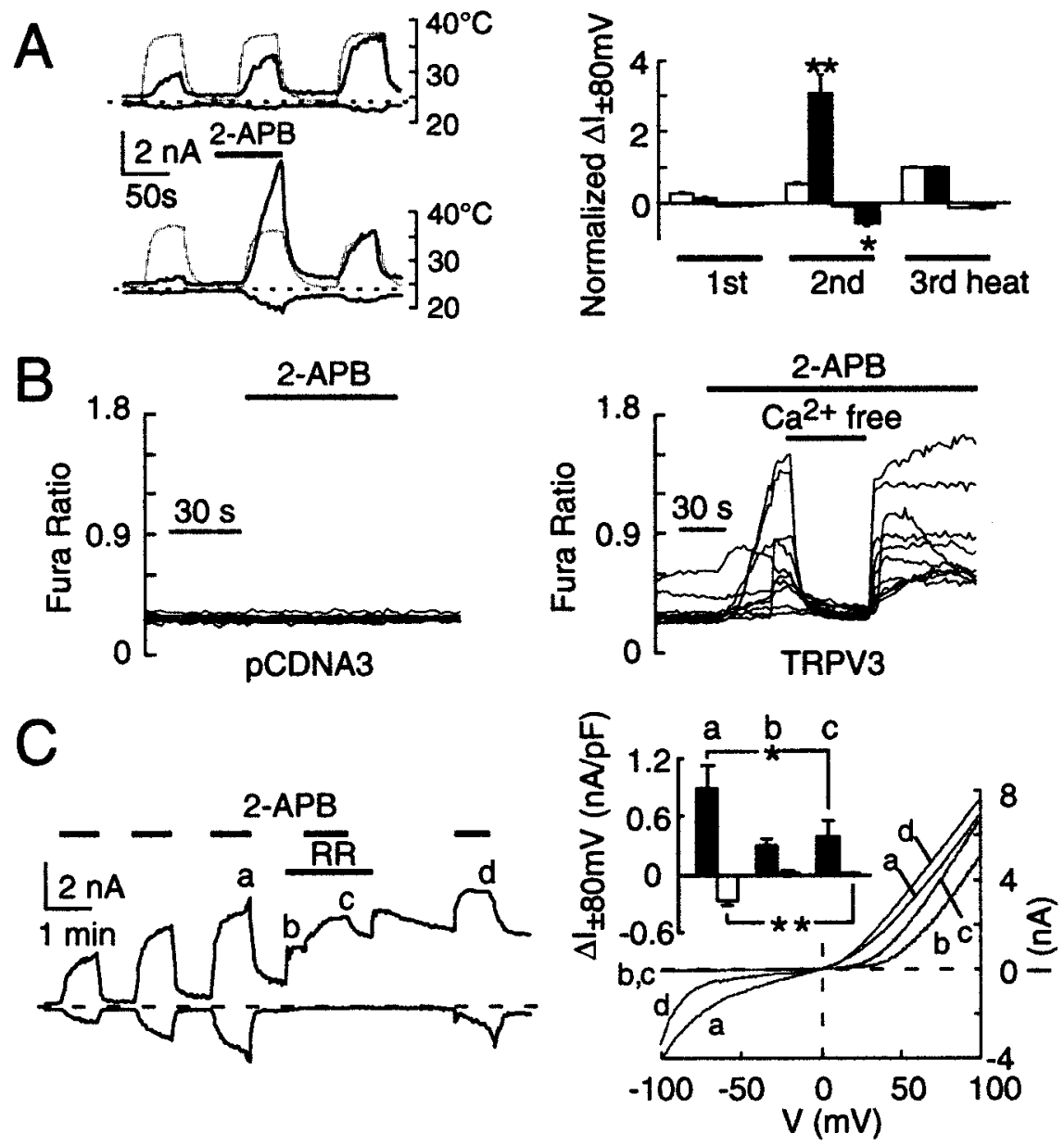

Figure 2. Properties of 2-APB-evoked currents in TRPV3-transfected HEK293 cells. A, 2-APB sensitization of heat-evoked TRPV3 currents in HEK293 cells. Left, Consecutive heat-evoked responses in the absence of 2-APB (top) or with $1 \mu \mathrm{m} 2$-APB present during only the second heat challenge (bottom). Right, Mean responses to consecutive heat challenges recorded in the absence (open bars) or presence (filled bars) of 2-APB during the second heat stimulus. For each cell, data were normalized to the peak amplitude of the third heat-evoked response at $+80 \mathrm{mV}\left(n=6\right.$; $\left.^{*} p<0.005 ;{ }^{* *} p<0.0005\right)$. $B$, Representative changes in intracellular $\mathrm{Ca}^{2+}$ in pCDNA3 (left) and TRPV3-transfected (right) HEK293 cells on application of $100 \mu \mathrm{m} 2-\mathrm{APB}$. Removal of extracellular $\mathrm{Ca}^{2+}\left(0 \mathrm{~mm} \mathrm{Ca}^{2+}, 10 \mathrm{~mm}\right.$ EGTA) reversibly decreased the 2-APB-evoked $\mathrm{Ca}^{2+}$ level to or below the prestimulus level. C, Left, Current amplitude changes in TRPV3-transfected HEK293 cells during successive applications of 2-APB (32 $\mu$ M) with RR (10 $\mu \mathrm{m})$ present during the indicated time period. Right, $\Delta I_{ \pm 80 \mathrm{mV}}$ at time points $a-d$, indicated in $C .\left(n=5 ;{ }^{*} p<0.05 ;{ }^{* *} p<\right.$ 0.005). Corresponding $I-V$ curves are shown at the bottom right. Dashed lines indicate zero current or potential level.

phenyl)propoxy]-4-methoxyphenethyl $1 \mathrm{H}$-imidazole hydrochloride $(40 \mu \mathrm{M})$, another inhibitor of store-operated $\mathrm{Ca}^{2+}$ entry, or diphenhydramine $(100 \mu \mathrm{M})$, a molecule structurally similar to 2-APB.

Next, we conducted single-channel recordings on inside-out membrane patches. At $25^{\circ} \mathrm{C}$, very few channel openings were observed. However, bath heating evoked a dramatic, temperature-dependent increase in single-channel openings (Fig. $3 A, B)$. These currents exhibited an almost linear $I-V$ relationship, with a reversal potential $\left(E_{\text {rev }}\right)$ of $\sim 0 \mathrm{mV}$ and inward and outward slope conductances at $39^{\circ} \mathrm{C}$ of 337 and $256 \mathrm{pS}$, respectively (Fig. 3C). 2 -APB $(1 \mu \mathrm{M})$ at $24^{\circ} \mathrm{C}$ also evoked singlechannel openings that were typically more prolonged than those evoked by heat (Fig. $3 A, B)$. As with heat, 2-APB-evoked responses exhibited a nearly linear $I-V$ relationship, with reversal near $0 \mathrm{mV}$ and inward and outward slope conductances of 201 and 147 pS, respectively (Fig. 3C). No such current responses to heat or 2-APB were observed in patches excised from HEK293 cells transfected with pCDNA3 (data not shown). Because the conductances of 2-APB- and heat-evoked currents were not identical, we asked whether TRPV3 unitary amplitude was temperature dependent. Recordings at $25-39^{\circ} \mathrm{C}$ revealed a linear increase in unitary amplitude with temperature for inward and outward currents (Fig. 3D,E). 2-APBevoked currents recorded at $25^{\circ} \mathrm{C}$ followed the same line, suggesting that the same channel is activated by heat and 2-APB. Together with the whole-cell data, these results demonstrate that 2 -APB can activate and potentiate recombinant TRPV3.

\section{2-APB potentiates TRPV3 \\ in keratinocytes}

TRPV 3 currents at $24^{\circ} \mathrm{C}, 2-\mathrm{APB}$ produced an approximately sixfold supra-additive enhancement of warmth $\left(37^{\circ} \mathrm{C}\right)$-evoked currents (Fig. 2A). Fluorescent $\mathrm{Ca}^{2+}$ imaging of HEK293 cells revealed robust 2 -APB-activated increases in intracellular $\mathrm{Ca}^{2+}$ in cells transfected with TRPV3, but not pCDNA3, at $24^{\circ} \mathrm{C}$. This increase was reversibly abolished by elimination of extracellular $\mathrm{Ca}^{2+}$, suggesting that it arises from $\mathrm{Ca}^{2+}$ influx through TRPV3, rather than release of internal $\mathrm{Ca}^{2+}$ stores (Fig. $2 \mathrm{~B}$ ). We next examined the effects of ruthenium red (RR), an antagonist of ion influx through most TRPV channels, including TRPV3 (Peier et al., 2002b; Smith et al., 2002; Xu et al., 2002). After several exposures to $2-\mathrm{APB}, 10 \mu \mathrm{M} \mathrm{RR}$ decreased the basal inward current exhibited by TRPV3-expressing HEK293 cells and potentiated the outward current at $24^{\circ} \mathrm{C}$ (Fig. 2C). Superimposition of $2-\mathrm{APB}$ onto RR resulted in no detectable inward current. Outward current increased slightly, but not as much as it had in the absence of RR (Fig. 2C, bar $c$ vs bar a). Application of 2-APB after RR washout resulted in large inward and outward currents. No TRPV3 activation was observed in response to $1-\{\beta$-[3-(4-methoxy-
We have reported previously that mouse keratinocytes exhibit two distinct current responses to warm temperatures: a TRPV4dependent desensitizing response observed in most cells and a sensitizing, strongly rectifying response that appears to be mediated by TRPV3. Immunofluorescence staining revealed that most keratinocytes expressed TRPV3. However, only $\sim 3 \%$ of them exhibited convincing TRPV3-like heat-evoked currents (Chung et al., 2004). We therefore examined the effects of 2-APB on primary mouse keratinocytes. At $24^{\circ} \mathrm{C}, 2-\mathrm{APB}(100 \mu \mathrm{M})$ produced a slight increase in current noise at strong positive potentials but no measurable change in whole-cell current (Fig. 4A). However, concomitant heating $\left(42^{\circ} \mathrm{C}\right)$ evoked a response distinct from that observed in the absence of 2-APB. In 22 of 27 2-APBtreated keratinocytes, repetitive heat challenges resulted in sensitizing, outwardly rectifying current responses. In some of these cells, the first heat response was biphasic, with an initial desensitizing component, followed by a gradually sensitizing component. This pattern strongly resembles that observed in keratinocytes exhibiting an additive TRPV4-like and TRPV3-like heat response (Chung et al., 

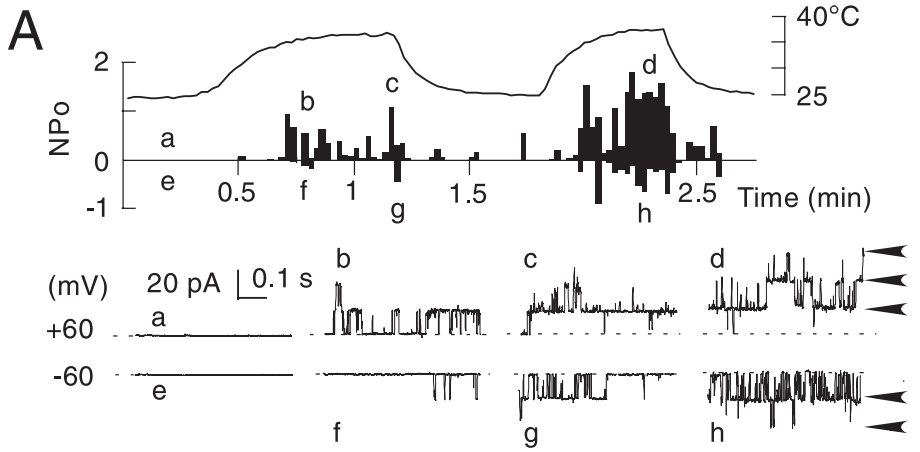
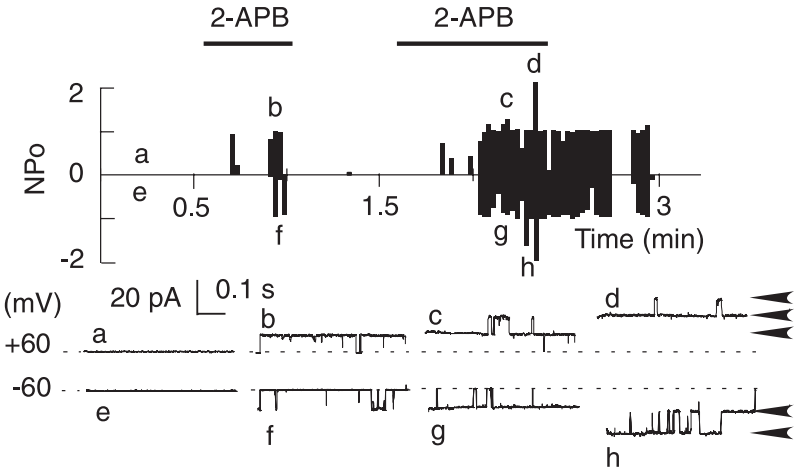

B

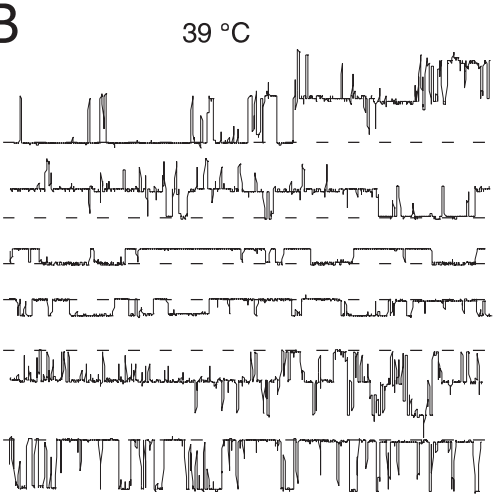

(mV)

$+90$

60

$+60$

$+30$

$-30$

$-60$

$-90$
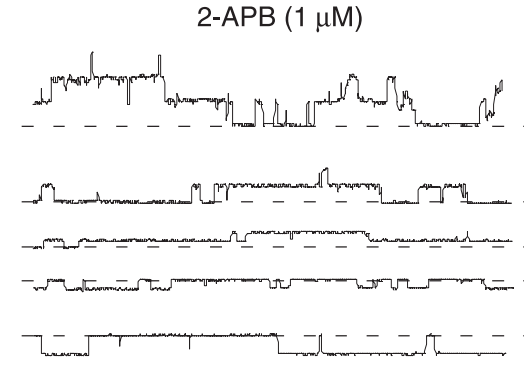

$20 \mathrm{pA}$

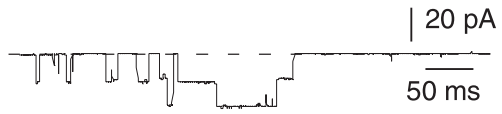

$E$

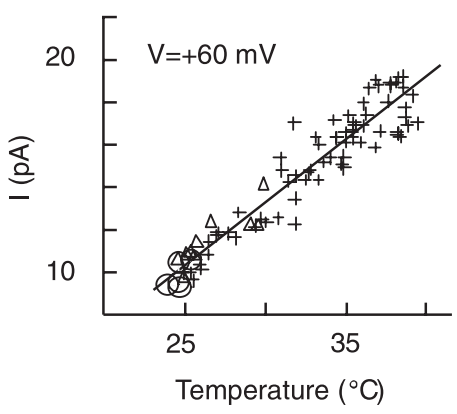

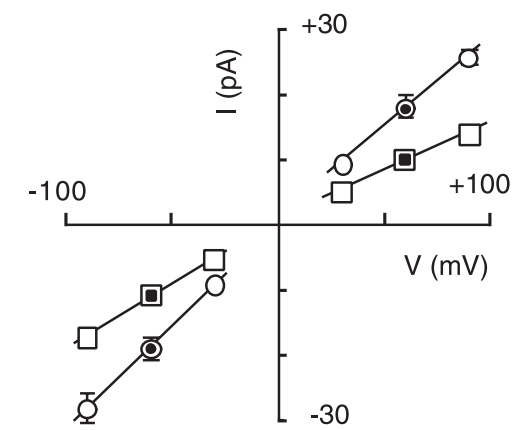

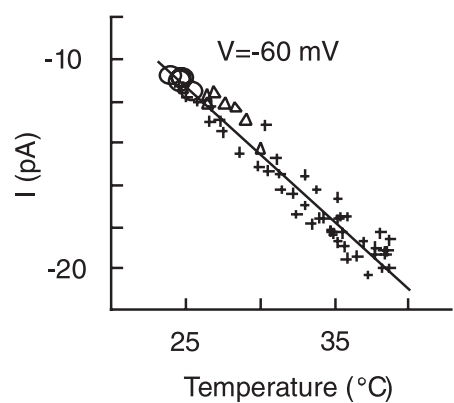

Figure 3. Single-channel currents evoked by heat and 2-APB in inside-out patches from TRPV3-transfected HEK293 cells. A, Changes in the open probability of multiple channels (NP0) after heating (left) or addition of $1 \mu \mathrm{m}$ 2-APB (right). Alternating 540-msec-step pulses to $\pm 60 \mathrm{mV}$ were repeated every $1.5 \mathrm{sec}$. Dotted lines indicate the closed channel state. Arrowheads indicate multiple-channel open states. At the bottom, $a-d$ and $e-h$ indicate currents recorded at $+60 \mathrm{mV}$ and $-60 \mathrm{mV}$, respectively, at the corresponding time points shown at the top. $B$, Representative single-channel currents evoked by heat $\left(39^{\circ} \mathrm{C}\right)$ or $2-\mathrm{APB}\left(1 \mu \mathrm{m}\right.$ at $\left.25^{\circ} \mathrm{C}\right)$ at various voltages. Dashed lines indicate closed channel state. $C, I-V$ relationship of single-channel currents evoked by heat (circles) or 2-APB (squares). $n=5$ patches per symbol. Small, filled squares and circles at $\pm 60 \mathrm{mV}$ indicate values derived from linear fit in $E$ at 25 and $39^{\circ} \mathrm{C}$, respectively. D, $E$, Temperature dependence of unitary TRPV 3 current amplitude. D illustrates representative currents evoked by 2-APB or heat. In $E$, unitary current amplitude is plotted as a function of temperature. To facilitate observation of channel openings over a broad temperature range, heat-evoked currents were recorded during both ascending (plus signs) and descending (triangles) phases of heat stimulus. Circles indicate 2-APB-evoked currents recorded at room temperature. Data were derived from eight independent cells. Lines indicate linear fit of heat-evoked current amplitudes $\left(\right.$ slope $=0.59, Q_{10}=2.0$ over $29-39^{\circ} \mathrm{C}$ at $+60 \mathrm{mV}$; slope $=0.63, Q_{10}=1.6$ at $-60 \mathrm{mV}$ ).

2004). Given that TRPV3 immunoreactivity in primary keratinocytes is primarily intracellular (Chung et al., 2004), we asked whether the effect of 2-APB was attributable to increased TRPV3 surface expression. Contrary to this prediction, 2-APB failed to visibly alter the keratinocyte TRPV3 immunostaining pattern (data not shown).

2-APB $(100 \mu \mathrm{M})$ application to keratinocytes derived from TRPV4 - / - mice again evoked only miniscule current responses at $24^{\circ} \mathrm{C}$. However, superimposed heat stimuli evoked large, outwardly rectifying currents $(60.1$ and $-10.8 \mathrm{pA} / \mathrm{pF}$ at $\pm 80 \mathrm{mV}$, $\left.n=7 ; E_{\mathrm{rev}}=1.3 \pm 1.1 \mathrm{mV}, n=12\right)$ in 23 of 30 cells (Fig. $4 B$ ) that sensitized with repeated heating. After 2-APB washout, baseline current at $24^{\circ} \mathrm{C}$ subsided, and only small heat-evoked responses were recorded. Addition of 2-APB in the middle of a heat challenge rapidly evoked large, outwardly rectifying current re- sponses in these cells (Fig. 4C). As in TRPV3-transfected HEK293 cells, RR $(10 \mu \mathrm{M})$ inhibited inward currents evoked by 2 -APB at $42^{\circ} \mathrm{C}$ in TRPV4 $-/-$ keratinocytes (Fig. $4 D$ ). When 2-APB was present at $24^{\circ} \mathrm{C}$, RR evoked an outward current (Fig. $4 D$, bar $c$ ) not seen previously without 2-APB (Chung et al., 2004) but dampened outward current responses to a superimposed heat stimulus (Fig. $4 D$, bar $b$ vs bar $d$ ). The former effect appears to reflect a synergistic interaction of subthreshold concentrations of RR and 2-APB that we observed in TRPV3-transfected HEK293 cells and TRPV4 -/- keratinocytes (supplemental Fig. 1, available at www.jneurosci.org). In transfected cells, the magnitude of this complex interaction varied as a function of drug dose and TRPV3 expression level (data not shown). Together, these properties lead us to conclude that TRPV3 is the likely mediator of 

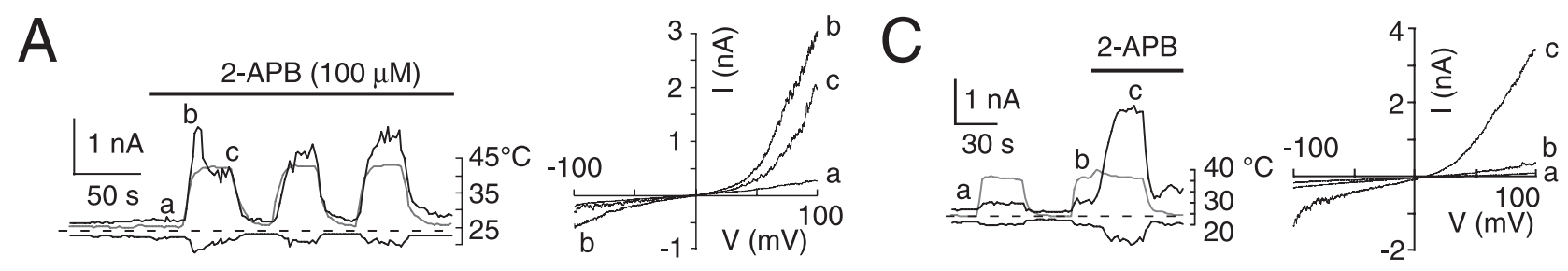

B
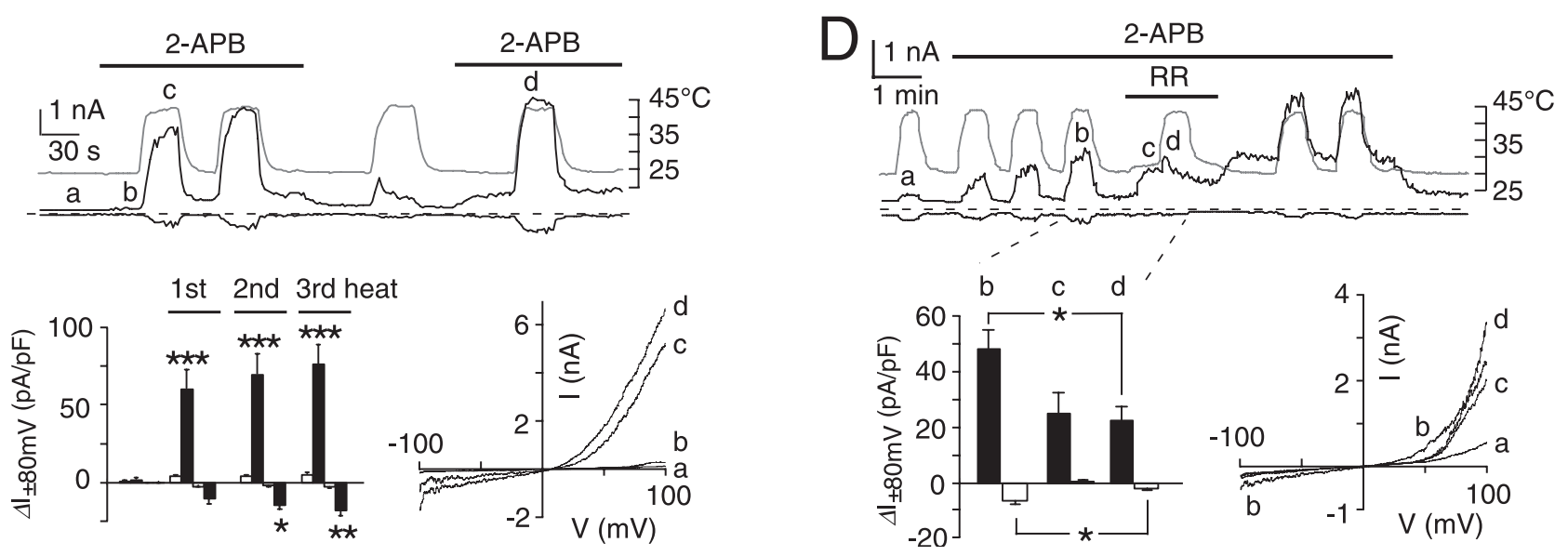

Figure 4. 2-APB sensitizes primary keratinocytes to heat. $A$, Current responses to $100 \mu \mathrm{m} 2-\mathrm{APB}$ plus heat in TRPV4 $+/+$ keratinocytes. The $I-V$ relationships shown to the right correspond to time points $a-c$, indicated to the left. $B$, Augmentation of heat-evoked currents in TRPV4 $-1-$ keratinocytes by 2-APB. Top, Representative current amplitude changes during successive challenges with heat in the presence or absence of $2-\mathrm{APB}(100 \mu \mathrm{m})$ at $\pm 80 \mathrm{mV}$. Bottom right, $I-V$ relationships at time points $a-d$, indicated at the top. Bottom left, $\Delta I_{ \pm 80 \mathrm{mV}}$ before and during three successive heat challenges in the presence (filled bars) or absence (open bars) of 2-APB. Heat-evoked responses in the absence versus the presence of 2-APB were recorded in separate cells ( $n=7$ for the 2-APB-treated group and 5 for the untreated group; $\left.{ }^{*} p<0.01 ; * * 0<0.05 ;{ }^{* * *} p<0.005\right)$. C, 2-APB (100 $\mu \mathrm{m}$ ) applied during heat stimulus enhances heat-evoked currents in TRPV4 $-/-$ keratinocytes. I-V relationships shown to the right were obtained at time points $a-c$, indicated to the left. D, Effect of RR on currents evoked by 2-APB and heat in TRPV4 - / - keratinocytes. Top, Current traces recorded during challenges with heat and 2-APB $(100 \mu \mathrm{M})$ with or without RR $(10 \mu \mathrm{M})$. Bottom, $\Delta I_{ \pm 80 \mathrm{mv}}\left(n=5 ;{ }^{*} p<0.05\right)$ (left) and $I-V$ relationships (right) at indicated time points. In all panels, horizontal dashed lines indicate zero current level.

2-APB-sensitized keratinocyte responses to heat and that such responses do not require TRPV4.

\section{Discussion}

2-APB has been used extensively as an inhibitor of store-operated $\mathrm{Ca}^{2+}$ influx and $\mathrm{IP}_{3}$-mediated $\mathrm{Ca}^{2+}$ release (Maruyama et al., 1997; Bootman et al., 2002). Although some have interpreted the effect on store-operated $\mathrm{Ca}^{2+}$ entry as reflecting direct action on cell-surface channels (Prakriya and Lewis, 2001), others have suggested an indirect effect, mediated through a common regulatory component that couples $\mathrm{Ca}^{2+}$ influx and $\mathrm{Ca}^{2+}$ release (Ma et al., 2002; Schindl et al., 2002). In some cases, 2-APB has been shown to stimulate rather than inhibit $\mathrm{IP}_{3}$ receptor-mediated $\mathrm{Ca}^{2+}$ release from intracellular stores, cell-surface store-operated $\mathrm{Ca}^{2+}$ channels, and a nonselective cationic current of unknown function (Prakriya and Lewis, 2001; Ma et al., 2002; Braun et al., 2003). Thus, the precise molecular target(s) and mechanism(s) of action of this drug remain unclear.

Among the proposed mediators of store-operated $\mathrm{Ca}^{2+}$ entry are TRP channels of the transient receptor potential canonical and TRPV subfamilies, some of whose activities can be modulated by 2-APB. Although most of these effects are inhibitory, one example of a positive effect of 2-APB on channel activity is that of TRPV6. Constitutive TRPV6 currents recorded in the presence of extracellular $\mathrm{Ca}^{2+}$ increase by $25 \%$ on addition of 2 -APB (50-75 $\mu \mathrm{M}$ ) (Voets et al., 2001; Schindl et al., 2002). 2-APB-evoked activation of TRPV3 is considerably more robust but exhibits a similar dose-response relationship. High 2-APB concentrations also produced extremely modest activation of TRPV1. However, we observed no activation of TRPV2 or TRPV4 by 2-APB, whereas
TRPV5 is partially inhibited by this compound (Nilius et al., 2001). Thus, 2-APB-evoked activation is not a universal trait among TRPV channels. The rapid onset and reversal of TRPV3 current activation and the activation of TRPV3 by 2 -APB in inside-out patches are consistent with a direct mechanism of action. Still, we cannot rule out the persistence of cytosolic components in these patches, and therefore cannot distinguish definitively between a direct activation mechanism and one mediated by a distinct regulatory factor (Schindl et al., 2002).

In this study, the single-channel amplitude of TRPV3 currents evoked by heat and 2-APB exhibited a linear $I-V$ relationship, in apparent contradiction to the outward rectification we observe at the whole-cell level and one previous report describing outwardly rectifying single-channel TRPV3 currents (Xu et al., 2002). The basis of these differences is unclear, but may include different recording modes (outside-out vs inside-out patch) or intracellular solution compositions. For example, a fourfold to 100 -fold higher intracellular free $\left[\mathrm{Mg}^{2+}\right]$ in the previous study might have produced outward rectification through divalent cation blockade of inward currents, as seen with $\mathrm{Ca}^{2+}$ and TRPV4 (Nilius et al., 2004). The difference between single-channel and whole-cell rectification may also be explained by an apparent voltage dependence of channel open probability, especially in the case of heat activation (Fig. 3A).

It is not clear why heat alone is insufficient to activate TRPV3 in the majority of primary keratinocytes. As suggested previously (Chung et al., 2004), this could stem from low levels of TRPV3 expression together with limited agonistic efficacy of heat. Low TRPV3 expression levels might accurately reflect the in vivo con- 
dition or be an artifact of keratinocyte culture (Peier et al., 2002b). Alternatively, cultured keratinocytes may lack obligate molecular cofactors for TRPV3 thermal responsiveness. Another possibility is that TRPV3 activity in keratinocytes is masked by phospholipids or other cellular constituents, as demonstrated for TRPV1 (Chuang et al., 2001). Regardless, 2-APB, which acts supra-additively with heat, appears to overcome these limitations by increasing TRPV3 gating or inhibiting its suppression.

TRPV3 modulation by endogenous molecules analogous to 2-APB (or other targets of this compound) might dictate TRPV3 in vivo responsiveness to heat or, in some tissues, represent its primary mode of regulation. Tight control over TRPV3 thermal activation apparently differs from that of TRPV4, the heatevoked activity of which is more readily observed in cultured keratinocytes (Chung et al., 2004). Together with their distinct kinetic properties, such differential regulation may reflect separate functions for these two channels in keratinocyte thermotransduction. Our results also indicate that TRPV3 activation may provide a facile readout for the identification of 2-APB targets. Conversely, as a chemical stimulus, 2-APB represents a potentially powerful tool for the physiological analysis of TRPV3 and the identification of clinically useful TRPV3 antagonists.

\section{References}

Alessandri-Haber N, Yeh JJ, Boyd AE, Parada CA, Chen X, Reichling DB, Levine JD (2003) Hypotonicity induces TRPV4-mediated nociception in rat. Neuron 39:497-511.

Bandell M, Story GM, Hwang SW, Viswanath V, Eid SR, Petrus MJ, Earley TJ, Patapoutian A (2004) Noxious cold ion channel TRPA1 is activated by pungent compounds and bradykinin. Neuron 41:849-857.

Bootman MD, Collins TJ, Mackenzie L, Roderick HL, Berridge MJ, Peppiatt CM (2002) 2-aminoethoxydiphenyl borate (2-APB) is a reliable blocker of store-operated Ca2 + entry but an inconsistent inhibitor of InsP3induced Ca2 + release. FASEB J 16:1145-1150.

Braun FJ, Aziz O, Putney Jr JW (2003) 2-aminoethoxydiphenyl borane activates a novel calcium-permeable cation channel. Mol Pharmacol 63:1304-1311.

Caterina MJ, Julius D (2001) The vanilloid receptor: a molecular gateway to the pain pathway. Annu Rev Neurosci 24:487-517.

Chuang HH, Prescott ED, Kong H, Shields S, Jordt SE, Basbaum AI, Chao MV, Julius D (2001) Bradykinin and nerve growth factor release the capsaicin receptor from PtdIns(4,5)P2-mediated inhibition. Nature 411:957-962.

Chung MK, Lee H, Caterina MJ (2003) Warm temperatures activate TRPV4 in mouse 308 keratinocytes. J Biol Chem 278:32037-32046.

Chung MK, Lee H, Mizuno A, Suzuki M, Caterina M (2004) TRPV3 and TRPV4 mediate warmth-evoked currents in primary mouse keratinocytes. J Biol Chem 279:21569-21575.

Guler AD, Lee H, Iida T, Shimizu I, Tominaga M, Caterina M (2002) Heatevoked activation of the ion channel, TRPV4. J Neurosci 22:6408-6414.

Jordt SE, Bautista DM, Chuang HH, McKemy DD, Zygmunt PM, Hogestatt ED, Meng ID, Julius D (2004) Mustard oils and cannabinoids excite sensory nerve fibres through the TRP channel ANKTM1. Nature 427:260-265.

Kanzaki M, Zhang YQ, Mashima H, Li L, Shibata H, Kojima I (1999) Translocation of a calcium-permeable cation channel induced by insulin-like growth factor-I. Nat Cell Biol 1:165-170.

Ma HT, Venkatachalam K, Parys JB, Gill DL (2002) Modification of storeoperated channel coupling and inositol trisphosphate receptor function by 2-aminoethoxydiphenyl borate in DT40 lymphocytes. J Biol Chem 277:6915-6922.

Maruyama T, Kanaji T, Nakade S, Kanno T, Mikoshiba K (1997) 2APB, 2-aminoethoxydiphenyl borate, a membrane-penetrable modulator of Ins(1,4,5)P3-induced Ca2+ release. J Biochem (Tokyo) 122:498-505.

McKemy DD, Neuhausser WM, Julius D (2002) Identification of a cold receptor reveals a general role for TRP channels in thermosensation. Nature 416:52-58.

Muraki K, Iwata Y, Katanosaka Y, Ito T, Ohya S, Shigekawa M, Imaizumi Y (2003) TRPV2 is a component of osmotically sensitive cation channels in murine aortic myocytes. Circ Res 93:829-838.

Nilius B, Prenen J, Vennekens R, Hoenderop JG, Bindels RJ, Droogmans G (2001) Pharmacological modulation of monovalent cation currents through the epithelial $\mathrm{Ca} 2+$ channel ECaC1. Br J Pharmacol 134:453-462.

Nilius B, Vriens J, Prenen J, Droogmans G, Voets T (2004) TRPV4 calcium entry channel: a paradigm for gating diversity. Am J Physiol Cell Physiol 286:C195-C205.

Patapoutian A, Peier AM, Story GM, Viswanath V (2003) ThermoTRP channels and beyond: mechanisms of temperature sensation. Nat Rev Neurosci 4:529-539.

Peier AM, Moqrich A, Hergarden AC, Reeve AJ, Andersson DA, Story GM, Earley TJ, Dragoni I, McIntyre P, Bevan S, Patapoutian A (2002a) A TRP channel that senses cold stimuli and menthol. Cell 108:705-715.

Peier AM, Reeve AJ, Andersson DA, Moqrich A, Earley TJ, Hergarden AC, Story GM, Colley S, Hogenesch JB, McIntyre P, Bevan S, Patapoutian A (2002b) A heat-sensitive TRP channel expressed in keratinocytes. Science 296:2046-2049.

Prakriya M, Lewis RS (2001) Potentiation and inhibition of $\mathrm{Ca}(2+)$ releaseactivated $\mathrm{Ca}(2+)$ channels by 2 -aminoethyldiphenyl borate (2-APB) occurs independently of IP(3) receptors. J Physiol (Lond) 536:3-19.

Schindl R, Kahr H, Graz I, Groschner K, Romanin C (2002) Store depletionactivated CaTl currents in rat basophilic leukemia mast cells are inhibited by 2 -aminoethoxydiphenyl borate. Evidence for a regulatory component that controls activation of both CaT1 and CRAC $(\mathrm{Ca}(2+)$ releaseactivated $\mathrm{Ca}(2+)$ channel) channels. J Biol Chem 277:26950-26958.

Smith GD, Gunthorpe MJ, Kelsell RE, Hayes PD, Reilly P, Facer P, Wright JE, Jerman JC, Walhin JP, Ooi L, Egerton J, Charles KJ, Smart D, Randall AD, Anand P, Davis JB (2002) TRPV3 is a temperature-sensitive vanilloid receptor-like protein. Nature 418:186-190.

Story GM, Peier AM, Reeve AJ, Eid SR, Mosbacher J, Hricik TR, Earley TJ, Hergarden AC, Andersson DA, Hwang SW, McIntyre P, Jegla T, Bevan S, Patapoutian A (2003) ANKTM1, a TRP-like channel expressed in nociceptive neurons, is activated by cold temperatures. Cell 112:819-829.

Suzuki M, Mizuno A, Kodaira K, Imai M (2003) Impaired pressure sensation in mice lacking TRPV4. J Biol Chem 278:22664-22668.

Voets T, Prenen J, Fleig A, Vennekens R, Watanabe H, Hoenderop JG, Bindels RJ, Droogmans G, Penner R, Nilius B (2001) CaT1 and the calcium release-activated calcium channel manifest distinct pore properties. J Biol Chem 276:47767-47770.

Watanabe H, Vriens J, Suh SH, Benham CD, Droogmans G, Nilius B (2002) Heat-evoked activation of TRPV4 channels in a HEK293 cell expression system and in native mouse aorta endothelial cells. J Biol Chem 277:47044-47051.

Watanabe H, Vriens J, Prenen J, Droogmans G, Voets T, Nilius B (2003) Anandamide and arachidonic acid use epoxyeicosatrienoic acids to activate TRPV4 channels. Nature 424:434-438.

Xu H, Ramsey IS, Kotecha SA, Moran MM, Chong JA, Lawson D, Ge P, Lilly J, Silos-Santiago I, Xie Y, DiStefano PS, Curtis R, Clapham DE (2002) TRPV3 is a calcium-permeable temperature-sensitive cation channel. Nature 418:181-186. 